\title{
Muro Mediterráneo versus movimiento moderno
}

\section{Mediterranean Wall versus modern architecture}

Andrés MARTÍNEZ-MEDINA

Universidad de Alicante

andresm.medina@ua.es

\section{Paolo SANJUST}

Università degli Studi di Cagliari psanjust@unica.it

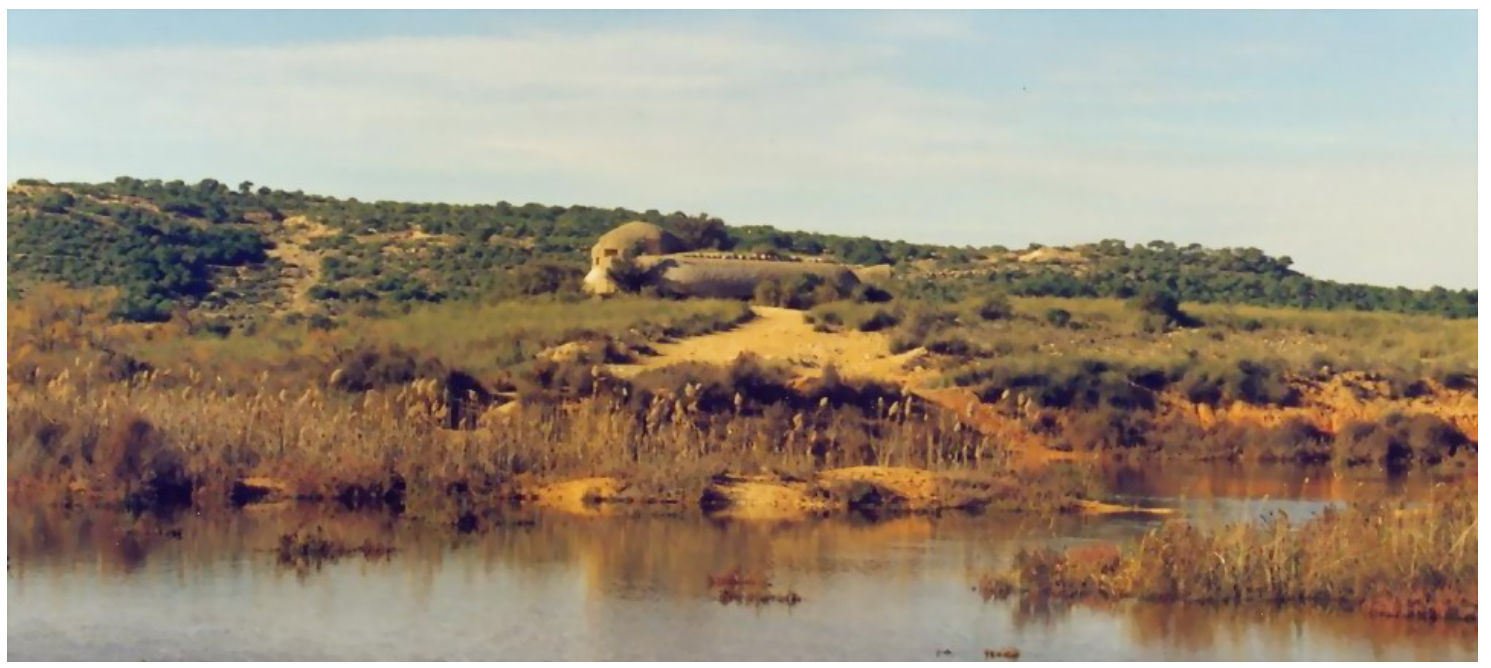

Fig.01: Búnker en la laguna del Clot de Galvany de Elche (ca. 1937-38, España) 


\title{
Resumen
}

Una década antes de que fuera construido el Muro Atlántico fue ejecutado un sistema de defensas a lo largo de la costa del Mediterráneo español (1936-39). La recuperación de estas construcciones (de sus documentos gráficos) y su puesta en valor pueden ayudar a consolidar una memoria propia del siglo XX. Este trabajo consiste en inventariar, medir y dibujar los planos de estas arquitecturas a fin de fijar la memoria que se diluye por la erosión del tiempo. Estas defensas militares se sitúan en muchas fronteras: ¿son propiamente arquitectura o piezas industriales? ¿Son arquitectura moderna? Estas transitan entre dos mundos: uno que proyecta arquitecturas ligeras, flexibles y con caducidad frente a otro que construye obras compactas, rígidas y eternas. También se mueven por dos épocas: una que perpetúa las hazañas épicas frente a otras que muestra los desastres. Espacio, tiempo y materia. Son las ruinas de hormigón más modernas de nuestra historia que se encuentran camufladas en la topografía: templos y tumbas a la vez. En esta reconstrucción de la memoria, resulta crucial la restitución gráfica que es donde comienza el conocimiento.

\section{Palabras Clave}

Muro Mediterráneo, defensas militares, arquitectura moderna

\begin{abstract}
A decade before there was getting up the Atlantic Wall, there was executed a system of defenses along the Mediterranean coast in Spain (1936-39). The recovery of the same constructions (both of his graphical documents) and his putting in value it can help to consolidate an own memory of the 20th century. This work considers to inventory, to measure and to draw the planes of these architectures to fix the memory that is diluted by the erosion of the time. These military defenses place in many borders: are these defenses properly architecture or are these industrial pieces? Are these a modern architecture? These are walking between two worlds: the one that designs lightweight, flexible and outdated and another that builds heavy, rigid and eternal works. These are walking between two epochs too: the one that perpetuates the epic acts in opposite to the one that shows the disasters. Space, time and matter. They are the most modern ruins of our history built with concrete and disguised in the topography: temples and tombs at the same time. In this reconstruction of the memory, there turns out to be crucial the graphical restitution which is the home of knowledge.
\end{abstract}

\section{Keywords}

Mediterranean Wall, military defenses, modern architecture 


\section{INTRODUCCIÓN: CONSTRUCCIÓN Y DESTRUCCIÓN, INGENIERÍA Y ARQUITECTURA}

"La defensa es para tiempos de escasez, el ataque para tiempos de abundancia" S. Tzu, ca. 500 aC.

Habitualmente realizamos una rápida asociación entre los pares paz y construcción y guerra y destrucción, idea que hacemos extensible a casi todos los campos, excepto al de la producción de armamento. Si hay conflicto bélico, suponemos, no se levantan arquitecturas. Pero no es así, la realidad es más compleja. Los enfrentamientos armados han necesitado siempre de obras que se erigen tanto en tiempos de paz como en tiempos de guerra. Toda guerra del siglo XX ha producido, además y como mínimo, dos tipos de artefactos específicos para sus demandas: los refugios para la protección de los civiles en caso de ataque y los fortines para la defensa de ciudades y su territorio circundante. Estos últimos se plantean como máquinas en posición de defensa ya que la arquitectura no se desplaza, se ancla al suelo. Existe una correspondencia entre estas piezas militares y la múltiple capacidad ofensiva de los ejércitos dotados de aparatos móviles a gran velocidad por tierra, mar y aire (Aracil 2010; Ruiz 2012).

La guerra que protagonizó España entre 1936 y 1939 puede entenderse como un eslabón más de la cadena de violencia que supuso la continua 'Gran Guerra Civil' europea (De la Flor 2000) que convirtió el continente en un gran teatro de operaciones bélicas durante tres décadas (1914-45). Desde las trincheras de la I guerra mundial hasta la planificación y ejecución del Atlantic Wall de la II guerra mundial tiene lugar una continua evolución y adaptación de las defensas que se construyen a las cada vez más sofisticadas tácticas de invasión y al aún más elaborado armamento y su capacidad para desplazarse. Máquinas estáticas -arquitectura- y dinámicas ingeniería- están en continua interacción. Y es en este proceso del 'arte de la guerra' (Tzu 500aC) donde se encuadra el conjunto de defensas que se construyen por toda la geografía española durante su conflicto, llegando a constituir, en alguna de sus partes y por la distribución de las piezas por el litoral, lo que podríamos denominar el "Muro Mediterráneo"; todavía son visibles muchos de estos elementos o de sus restos (Figs. 01, 02, 05, 10, 14 y 15), aunque casi nada quede de sus planos. Es obvio que lo sucedido en España no se considera, desde ningún punto de vista, un caso aislado, sino enlazado a una historia de más larga duración por lo que respecta a cuestiones políticas y a las estrictamente disciplinarias de la industria y la arquitectura.

En este panorama resulta interesante descubrir las relaciones que guardan las formas arquitectónicas como respuesta al poder destructivo de la munición trazando los vínculos que dibujan y materializan el volumen de estos artefactos frente a los ingenios bélicos. Después de todo siempre ha sido así: la arquitectura, desde su primera misión de protección (valla, cerca, muro), ha definido -históricamente- sus contornos en atención a oponer la máxima resistencia al poder ofensivo del enemigo. Entre forma arquitectónica -respuesta- y función balística -pregunta- siempre se ha perfilado una gráfica óptima de relaciones y resultados eficaces. Es evidente que no son objeto del presente texto ni el porqué de la guerra (que no resolvieron Einstein y Freud en su correspondencia), ni los aspectos estéticos (positivos o negativos) que se pudieran derivar del extenso patrimonio abandonado que aún queda en pie en ruinas (porque 
eso son las ruinas: obras que ya no se usan, al margen de su estado material). Las guerras y sus estéticas transitan por campos complejos y contradictorios y aquí nos interesan las certezas que aporta la ciencia del dibujo cuando se erige en la herramienta capaz de restituir los planos y mapas que la urgencia de los acontecimientos impidió se conservaran. Todo ello con el fin de registrar y documentar las defensas para construir una memoria de las guerras que el tiempo no diluya.

Una nueva sensibilidad que atestiguan los desastres de esta Gran Guerra Civil es la idea compartida de que los monumentos ya no deben serlo sólo a las hazañas heroicas -individuales- y a las gestas épicas -colectivas-. Un sentimiento de culpabilidad acompaña a la humanidad desde entonces por lo que, a menudo, gobiernos e instituciones piden perdón a los ciudadanos del mundo por las guerras y otras calamidades. Entre los cementerios proyectados por E. Lutyens en Francia (ca. 1920) y el Centro de la Paz en Hiroshima de K. Tange (ca. 1950) se consolida una nueva conciencia sobre la vergüenza de lo acontecido que se refleja, antes, en las obras nuevas conmemorativas y, después, en los lugares y los vestigios que fueron escenario de las contiendas o sus masacres. Los restos arquitectónicos del pasado atroz se vuelven reliquias a conservar para perpetuar el recuerdo de los hechos y que no caigan en el olvido. Dentro de este cambio de paradigma (de héroes a villanos), y por lo que respecta a monumentalizar las arquitecturas de las guerras como testigos mudos de atrocidades y miedos, debe destacarse la labor del filósofo Paul Virilio quien, desde 1958, contribuyó a valorar los fosilizados búnkeres de la II guerra mundial esparcidos por la orografía europea, volviendo arqueología lo que fue arquitectura en uso (Virilio 1975).

Bandos militares a parte, las arquitecturas de estas guerras contemporáneas acusan rasgos plásticos y expresivos que las catapulta a convertirse en un memorial. Al igual que otras muchas obras ya obsoletas producidas tras la revolución industrial, amplían el concepto y el espectro del patrimonio arquitectónico por sus valores antropológicos. De este cambio cultural ante los desastres entran a formar parte las defensas de la guerra de España que no han sido suficientemente valoradas hasta hoy, aunque ya comienzan a surgir voces, estudios, catálogos y planes que las señalan y protegen. En ningún supuesto se considera estas arquitecturas abandonadas a lo largo del litoral mediterráneo español como un caso aislado y acotado en la geografía y en el tiempo, sino que las entendemos como un episodio más en la escalada de tensión y violencia que continuaría a lo largo del siglo XX: Italia en la II guerra mundial (Figs. 02 y 15), Albania en la posguerra, Argelia en su guerra independencia, Yugoeslavia en su guerra civil o la Libia de Gadafi. Si las máquinas son el paradigma formal y funcional de la arquitectura moderna, procede preguntarse si estas arquitecturas de las guerra estratégicamente diseminadas por las costas del mar Mediterráneo- son o no modernas. 


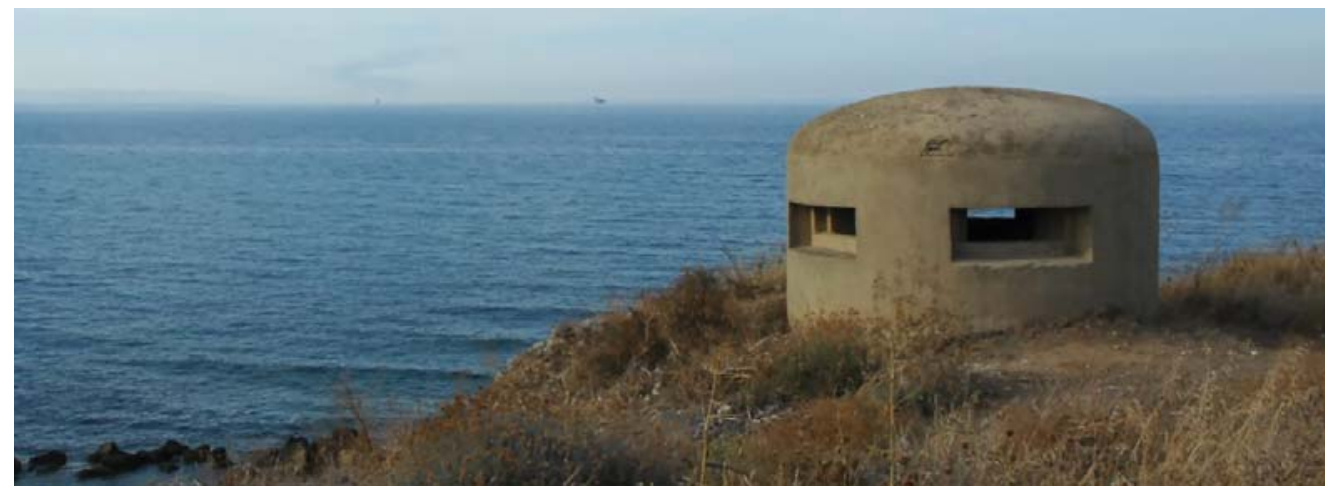

Fig. 02: Búnker en el litoral de Calabria (ca. 1942-44, Italia)

\section{2.- OBJETIVOS Y METODOLOGÍA: TRABAJOS DE CAMPO, HALLAZGO DE INVENTOS Y REFLEXIÓN TEÓRICA}

El carácter destructivo sólo conoce una consigna: hacer sitio; sólo una actividad: despejar. (...) Destruir rejuvenece, ya que aparta del camino las huellas de nuestra edad". W. Benjamin, ca. 1931

\section{1.- Método de investigación y límites de actuación}

El presente artículo pretende contribuir al inventariado, catalogación y conservación del conjunto de defensas de la guerra civil española al mismo nivel que lo están todas las arquitecturas militares anteriores al siglo XX. ¿Acaso existe, más allá de la edad, alguna diferencia sustancial entre el sistema de torres vigía del siglo XVI -también esparcido por todo el Mediterráneo- y la malla de defensas del siglo XX, ambas redes de vigilancia, control e información? (Martínez 1997). Para ello se sigue un método asentado desde la llustración y que $F$. Choay ( $F$. Choay 2007) resume en: $1^{\circ}$ ) descubrir (y valorar), $2^{\circ}$ ) inventariar (y clasificar), $3^{\circ}$ ) estudiar (sistemáticamente) y $4^{\circ}$ ) proteger (según el contexto); para después quedarían las intervenciones. No se puede valorar aquello que se desconoce. Conocer exige inventariar y clasificar. Para clasificar se requieren datos mensurables que se obtienen localizando las piezas (cartografías) y dibujándolas (planimetrías). El primer paso es el del hallazgo de los 'inventos' (o de sus restos) para iniciar la cadena de conocimiento que nos conduce a la valoración cultural y su posterior protección como legado.

Nuestro ámbito de investigación se concentra en el entorno de Alicante, última capital de la II República. El conjunto de búnkeres situados sobre las carreteras de acceso a la ciudad y los apostados sobre toda la costa forman parte de un sistema de defensas más extenso que pretendía blindar el litoral frente a los ataques por tierra, mar y aire. Esta red de elementos, aparentemente independientes, constituye un fragmento del que hemos denominado Muro del Mediterráneo, construido por el ejército republicano en el trienio de guerra y que se extiende desde Cádiz hasta Gerona, terminando por incorporar arquitecturas militares de ambos bandos. El conjunto de ruinas actuales está constituido por una red de construcciones que incluía búnkeres, blocaos, depósitos, trincheras, casamatas, nidos, baterías, puestos de mando, observatorios y otros tantos 
tipos de fortines que se esparcían por el territorio configurando una malla de piezas aisladas, cuyos nodos ocupan posiciones relevantes de la topografía atendiendo a leyes tácticas de control del despejado espacio bélico. Este diseminado de defensas militares por el territorio anticipa la ulterior dispersión de las metrópolis contemporáneas, insinuando una histórica y estrecha relación entre guerra y ciudad: los planteamientos de la arquitectura militar se trasladan con posterioridad al planeamiento urbano. De siempre, la arquitectura militar se ha situado por delante de las ciudades, primero acorazándolas para, con posterioridad, distanciarse de ellas y, finalmente, emplazarse por el medio porque, en las guerras contemporáneas, no se conquistan urbes, se dominan territorios.

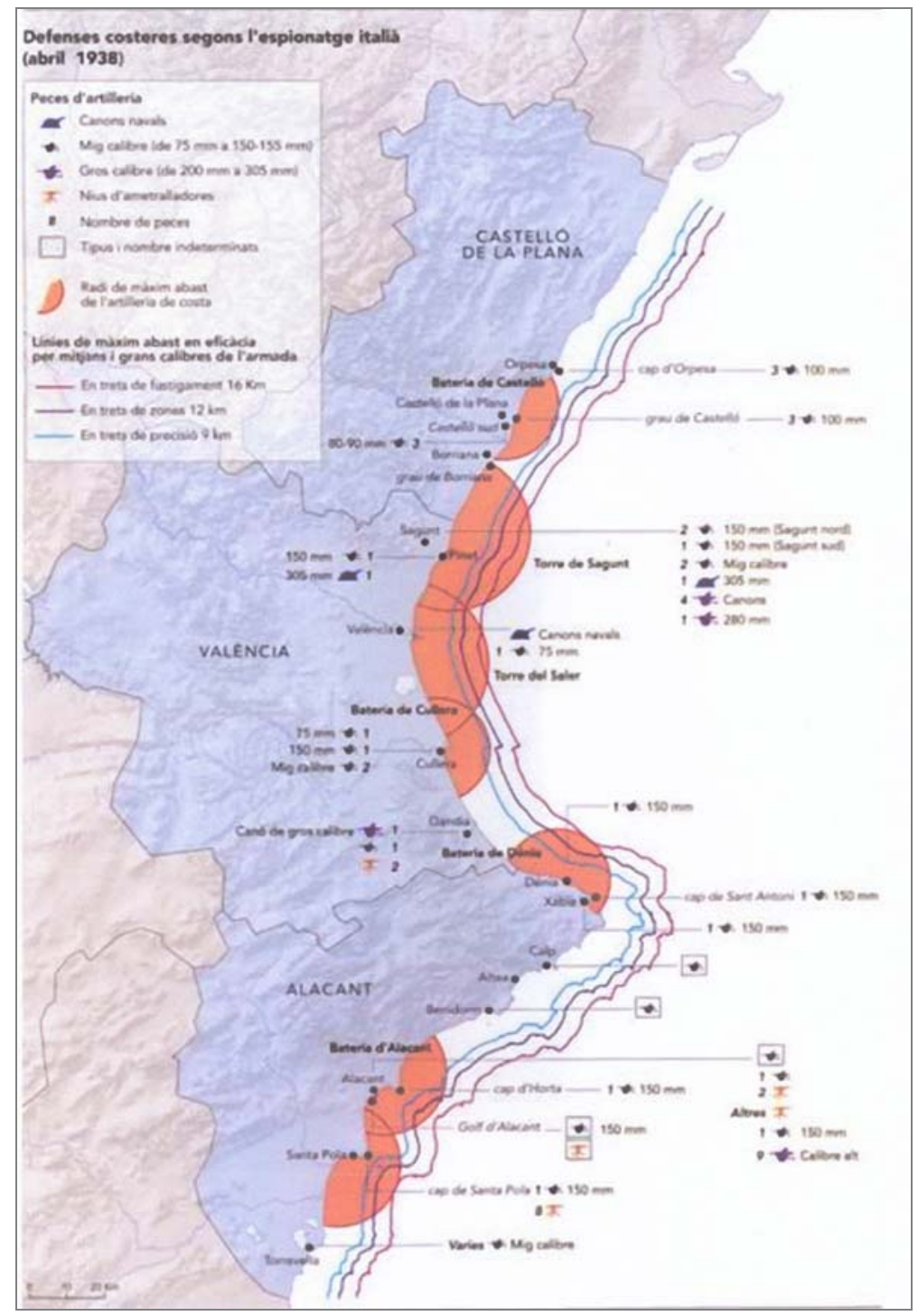

Fig.03: Defensas de la Comunidad Valenciana que definen el Muro Mediterráneo

El descubrimiento de las piezas nos permite su observación, descripción, inventariado, medición, alzamiento, escalado y diseccionado en su geometría y en su materia, 
restituyéndolas a facsímiles de los planos originales de los que poco se conserva. En resumen: se inicia el conocimiento. Estos documentos ya permiten clasificar y comparar los distintos elementos, tarea especialmente relevante en una arquitectura cuyo desarrollo, entre guerras, corre a la par que la difusión y afianzamiento de la conocida arquitectura del movimiento moderno. ¿Existe alguna relación entre esta última, resultado de la interacción de distintas vanguardias arquitectónicas, y las defensas militares situadas a la vanguardia de cualquier posición sobre el terreno? Estas piezas, en principio, tan lejanas de la arquitectura moderna, aunque solo sea por su aparente vocación de eternidad y su nula vinculación teórica y mediática con ella, han sido sugeridas como "iconos de la modernidad" (Postiglione 2008) por la vecindad de sus formas a algunos imaginarios de vanguardia y por la materia con la que se han construido: el hormigón armado. Una comparación de sus características básicas de forma y espacio, función y tiempo y material técnico, puede precisar las relaciones que guardan estas arquitecturas militares con las del movimiento moderno más allá de la apariencia de la imagen. Este análisis se efectúa sobre los restos del Muro Mediterráneo, pero sería extensible al Atlantic Wall y a las demás piezas de este complejo sistema de defensas, para fundamentar su valor cultural desde la técnica (más allá de sus valores antropológicos): desde la interacción de los procesos de industria y arquitectura. Piezas militares que son inventos, cuya reunión genera un inventario: la colección de inventos que se confirma y a la que se suman los que salen a la luz en el trabajo de campo. Porque invento (que procede del latín inventum) se define como "acción y efecto de inventar", lo cual no es otra cosa que "hallar o descubrir algo nuevo o desconocido", según el diccionario.

El 'muro', en los convencionalismos gráficos, se representa por una línea y toda línea no es más que la suma de puntos, por lo que podríamos ver el Muro Mediterráneo como el muro discontinuo construido con cada uno de los artefactos para la guerra. Este artículo -que se inicia en el redescubrimiento y construcción de este Muro Mediterráneo que no tuvo un proyecto unitario, sino que resulta de la suma de acciones parciales- trata de ser el primer paso en una investigación mucho más amplia y vasta: la de la catalogación de todas estas defensas para su protección en atención a los valores disciplinares en relación al concepto de arquitectura moderna, que evidencian la cultura de su época, constituyendo un monumento para ser transmitido en herencia ya que "Jamás se da un documento de cultura sin que lo sea a la vez de la barbarie" (Benjamin 1973). Pero también constituye una reflexión sobre conceptos de arquitectura. La estratégica disposición diseminada de estas piezas por accidentes topográficos facilita su conservación y su condición telúrica -muchas de ellas están en parte excavadas- evoca la proximidad de sus fines: preservar la vida a costa de la muerte. Estos emplazamientos han sugerido que las piezas se camuflen entre los relieves y se confundan con el terreno, mimetizándose con él desdibujando las líneas del frente; un frente de batalla que se contraía o dilataba ante la aviación. Unos límites desplazables que se delimitaban con mojones mediante la inserción de estas defensas sobre el suelo. Piezas que, en su disposición, definían las fronteras físicas móviles y se situaban en otras fronteras: ¿eran arquitectura o ingeniería? Y si eran arquitectura ¿lo eran moderna? Es más ¿eran propiamente arquitectura si a esta se le supone hecho habitable que trasciende lo constructivo? Las respuestas no son ni simples ni inmediatas, porque se trata de una arquitectura de fronteras tangibles que traza sus propias fronteras disciplinares, situándose por delante y en los márgenes. 


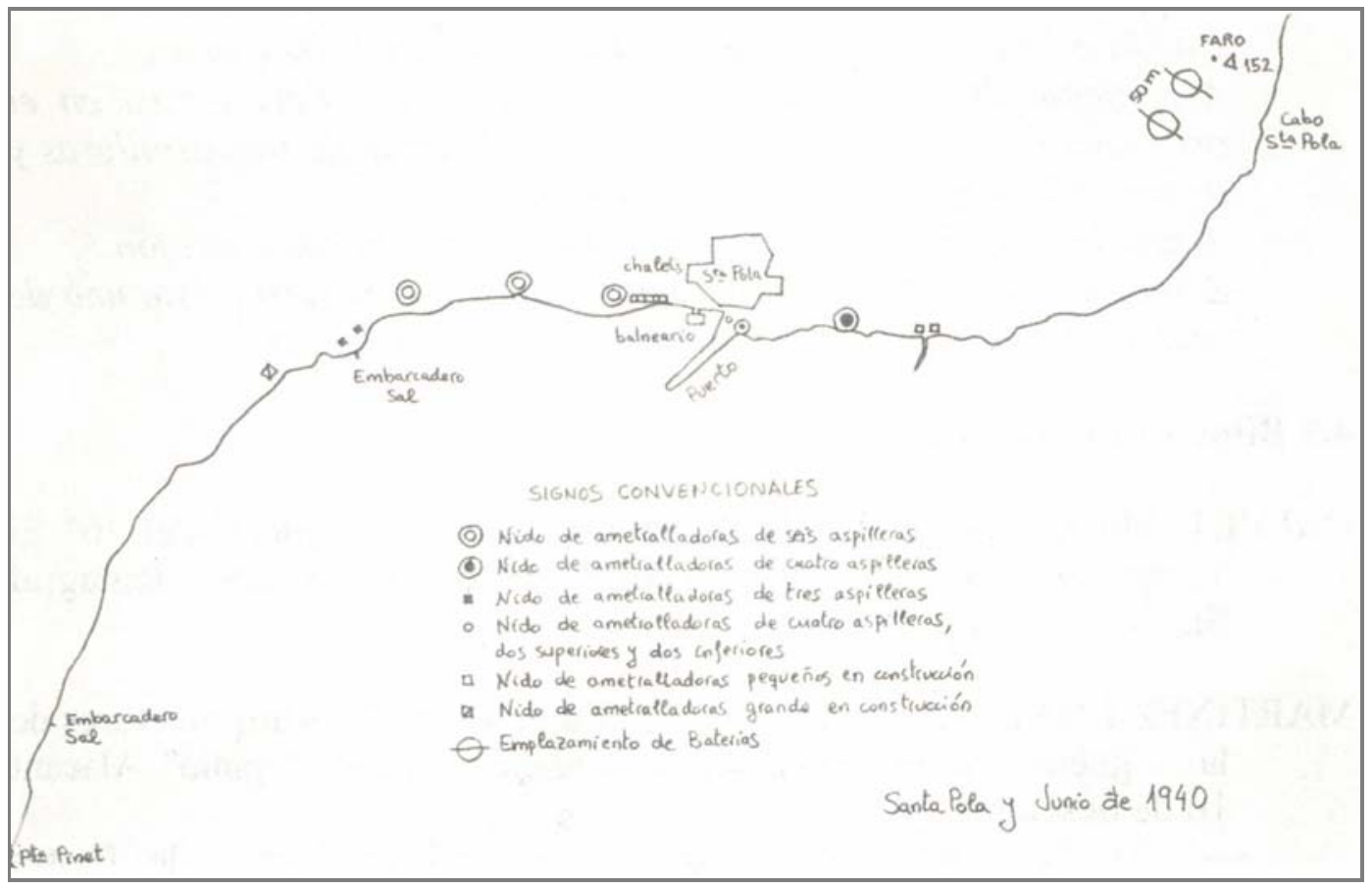

Fig.04: Inventario de las defensas en la bahía de Santa Pola (1940, España)

\section{2.- Geografías de la guerra: la toma de muestras}

El territorio barrido por los trabajos de campo para descubrir e inventariar las defensas del Muro Mediterráneo (búnkeres y baterías) se localiza en los accesos a la ciudad Alicante y en el frente marítimo de esta provincia. Varios son los parajes en los que se han descubierto piezas que pueden agruparse en dos situaciones geográficas diferentes: las infraestructuras que alcanzan la última capital republicana, por un lado, y la línea de costa urbana y rural del litoral, por otro. La geografía de las infraestructuras -conformada por enclaves junto a las carreteras nacionales de Madrid, Alcoy, Murcia y Cartagena- está constituida por los asentamientos de El Portichol (7 uds), Rabasa (2 uds), Bacarot (2 uds) y parte del Clot de Galvany (3 uds). La geografía del frente costero, y de sur a norte (Figs. 03 y 04), se construye con los asentamientos de las playas del Tamarit y Gran Playa (5 uds), cabo de Santa Pola (9 uds), Clot de Galvany (6 uds), playa de Babel (1 ud), serra Grossa (4 uds), cabo de Huertas (4 uds), playas de Benidorm y de Altea (5 uds), litoral de Jávea (2 uds) y costa de Denia (5 uds). Este inventario inicial da la cifra de 14 piezas junto a las infraestructuras y 41 piezas sobre la costa, lo que supone un total de más de medio centenar de ingenios de defensa a los que cabría sumar las arquitecturas de intendencia (cuarteles, polvorines, almacenes, trincheras, etc.). En general, estas piezas presentan fechas de ejecución -grafitis o inscripciones- que las datan en el bienio de 1937-38 (Figs. 01, 05, 06, 10, 11, 12 y 15).

El apoyo para localizar las diferentes piezas se ha basado en distintas informaciones bibliográficas y de hemeroteca dispersas sobre estas arquitecturas de la guerra y parte de su razón de ser: los bombardeos aéreos. Especialmente relevantes para el rastreo y para recrear una cartografía de las defensas del Muro Mediterráneo son las que se 
generan en cascada de escalas, de mayor a menor, desde los referentes a los objetivos urbanos junto al Mediterráneo de la aviación italiana (Martínez 2005), a los del armamento en el litoral del País Valencià (Aracil 2010 y Ruiz 2012) (Fig. 03) y a los del inventariado de construcciones y armas de algunos frentes litorales realizados por el ejército nacional al final de la contienda (García 2000) (Fig. 04). En este último resulta significativo que en el listado de defensas (1940) se efectúe una división tipológica por usos (baterías de costa frente a nidos de ametralladoras o búnkeres) y que estas últimas se clasifiquen por el número de aspilleras (de 3,4 o 6), lo que denota la importancia del campo visual de tiro facilitado por las rasgaduras horizontales que barren el espacio bélico a la altura del armamento y los ojos de los soldados en ángulos que oscilan entre 135 y 225 grados y que en algunos casos alcanzó los 360 (Rabasa). También han servido de gran ayuda los planes generales o especiales, así como los catálogos de bienes protegidos de algunas ciudades, como el caso del Plan de Protección de las Torres de la Huerta de Alicante (Mójica 2002) y el recientemente redactado para el Clot de Galvany en Elche (Tabar 2011).

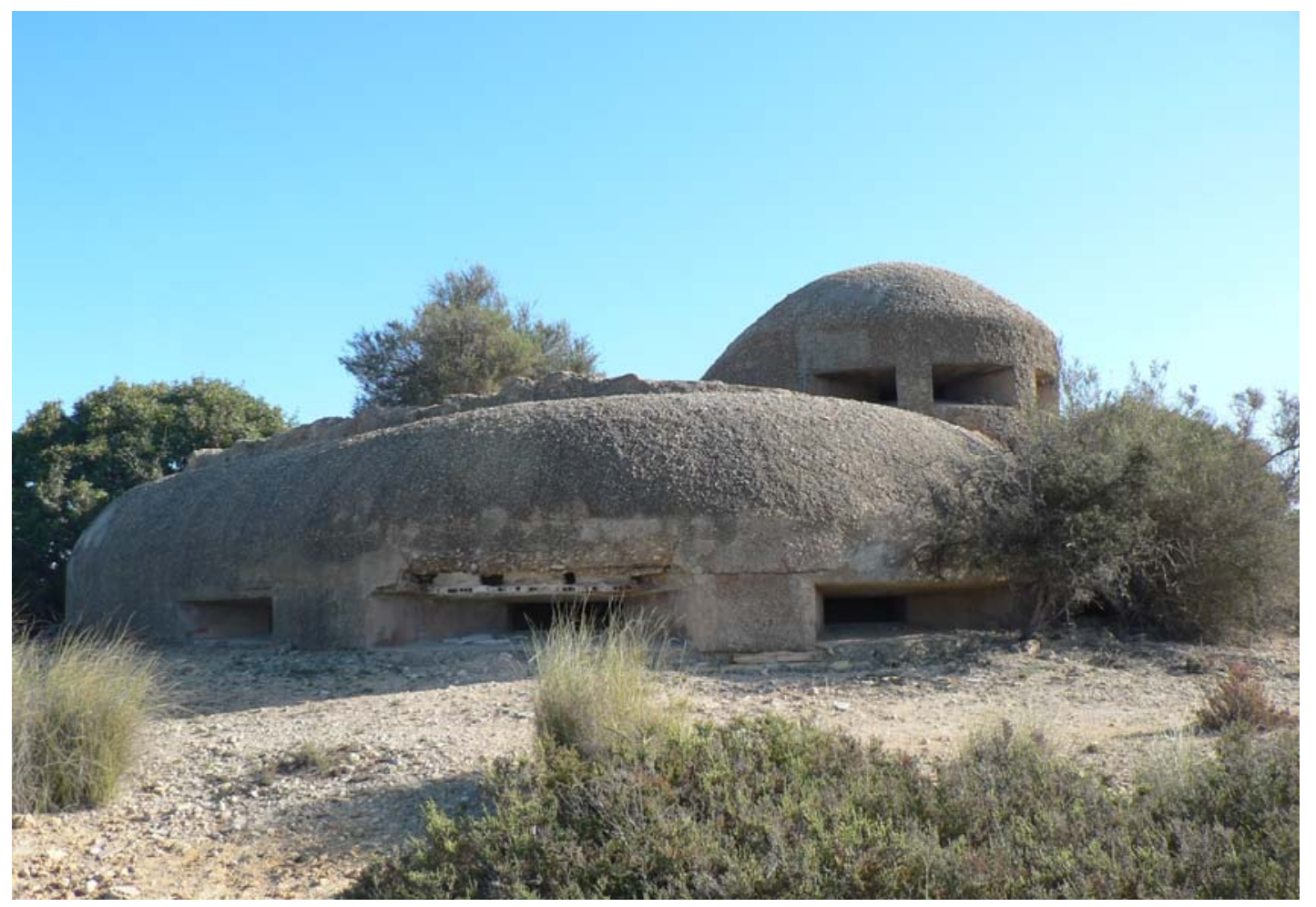

Fig.05: Detalle búnker existente en el Clot de Galvany en Elche (1937-38, España)

\section{3.- DESARROLLO DE LA INVESTIGACIÓN: MURO MEDITERRÁNEO VERSUS MOVIMIENTO MODERNO}

"La guerra es bella, ya que crea arquitecturas nuevas como las de los tanques, la de las escuadrillas formadas geométricamente, la de las espirales de humo de las aldeas incendiadas y muchas otras..." F.T. Marinetti (ca. 1910)

El trabajo presenta dos partes claramente diferenciadas. La primera se refiere a la toma 
de datos in situ, a los trabajos de campo: la geografía barrida y las arquitecturas inventariadas, medidas y dibujadas; es la que ya ha sido sintetizada y se reproduce gráficamente en algunas de sus plantas más significativas en un estado ideal que se le supone a los planos que sirvieron para su traza y construcción. La segunda se ocupa del análisis y estudio de dichos elementos mediante su comparación respecto de los principios de la arquitectura moderna de vanguardia (de 'entre guerras'), así como de su anclaje al entorno (a la topografía del territorio donde se implantan). Para tratar de acotar los distintos límites por los que transitan estas arquitecturas del Muro del Mediterráneo respecto de sus coetáneas del movimiento moderno, se ponen en relación aspectos básicos de los conceptos de espacio, programa, materia y lugar.

\section{1.- Espacio compartimentado}

Para el análisis comparativo entre ambos tipos de arquitecturas conviene comenzar por lo que se percibe visualmente (superficie y volumen) porque el hombre, en sus procesos de conocimiento, es mucho más visual que dependiente de cualquier otro sentido, aspecto en el que se basan las matemáticas de Benoît Mandelbrot que estudian los fractales. Seguramente sea en los aspectos de 'Forma y Espacio' donde más distancias descubrimos entre las arquitecturas militares y las del movimiento moderno. La principal característica del espacio moderno (contenido en sus volúmenes) es su isotropía: la carencia de direccionalidad y la liberación tanto de las particiones como de la envolvente de misiones resistentes; a ella contribuye el empleo del nuevo sistema de estructura porticada que facilita la carencia de direccionalidad. Todo ello se traduce en exteriores livianos, apariencia que no tienen estas piezas castrenses. Las defensas no sólo transmiten la imagen de macizos y casi inexpugnables fuertes, es que lo son. La prueba más cuantificable es que la opacidad se extiende por el $90 \%$ de su piel. Que las aspilleras sean horizontales, recorran el frente y se sitúen a la altura de los ojos, tiene más que ver con un objetivo táctico (abarcar la máxima visión con la mínima abertura) que con un criterio de apropiación del paisaje para atraerlo dentro. Más que como artefactos que contemplan hay que entenderlas como ingenios que escudriñan fortificados por una coraza hermética.

La visión paralela al plano de tierra, hacia la que se deslizan todas las arquitecturas del siglo $\mathrm{XX}$, está muy relacionada con la transformación del espacio que se inicia en el renacimiento cuando el Hombre sustituye a Dios (visión vertical) en el centro de los pensamientos, ya que estos se guían instintivamente por el sentido de la vista y el conocimiento se genera por el miedo a carecer de respuestas. $Y$ las guerras son miedo y sus arquitecturas lo perpetúan en tiempos de paz. Que los medios mecánicos de visión y observación (desde los anteojos al cine) se aproximen al modo de ver humano, asemeja una evolución lógica. Así pues, más que como artefactos que contemplan el horizonte haya que entender estas defensas como ingenios que otean el territorio a la vez se blindan. Su forma no es, pues, abierta, sino cerrada y compacta. 

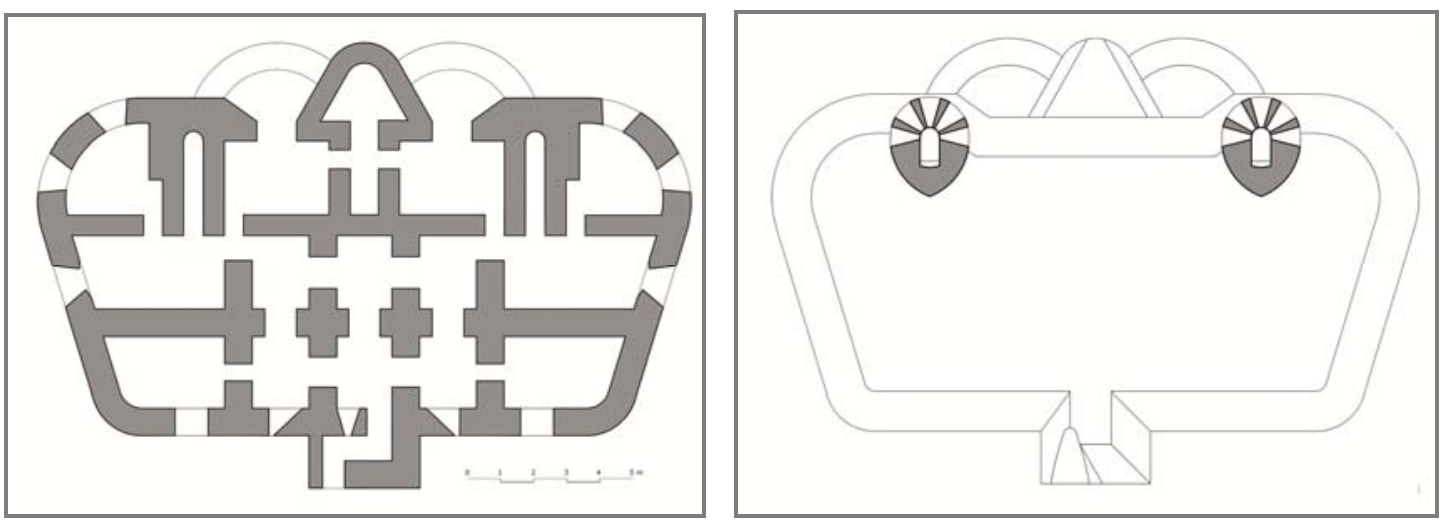

Figs.06: Plantas del búnker en el Clot de Galvany en Elche (1937-38, España)

Otra cuestión es la distribución interna. Mientras los espacios modernos ofertan su versatilidad, los búnkeres presentan cuartos delimitados y rígidos, definidos por muros estructurales que aumentan la resistencia frente al impacto (Figs. 05, 11, 12 y 13). El interior se defiende de la agresión gracias a la compartimentación. Entre elementos portantes y elementos de división no hay independencia, sino que los contrafuertes trituran el espacio en diminutos habitáculos casi sagrados. Estos búnkeres se aproximan más a la acertada expresión de ser "pequeños templos sin religión" (Postigioni 2008), afirmación que se corrobora porque todo espacio sagrado se caracteriza por estar cerrado por un muro. Quizás sea presuntuoso acercar lo sagrado a estas arquitecturas que atestiguan el debate entre la vida y la muerte de sus moradores, pero la extraña coincidencia de alguna de las fortalezas de la Ligne Maginot francesa (Fig. 07), terminada en 1936, con el proyecto de Le Corbusier para la Basilique de la Paix et du Pardon (1945, La Sainte-Baume), excavada en la montaña (Fig. 08), confirma esta afinidad en el homenaje que el maestro rinde a la arquitectura militar semienterrada como la ideal para proyectar uno de sus primeros espacios religiosos volviendo a los inicios de la arquitectura, a la cueva.

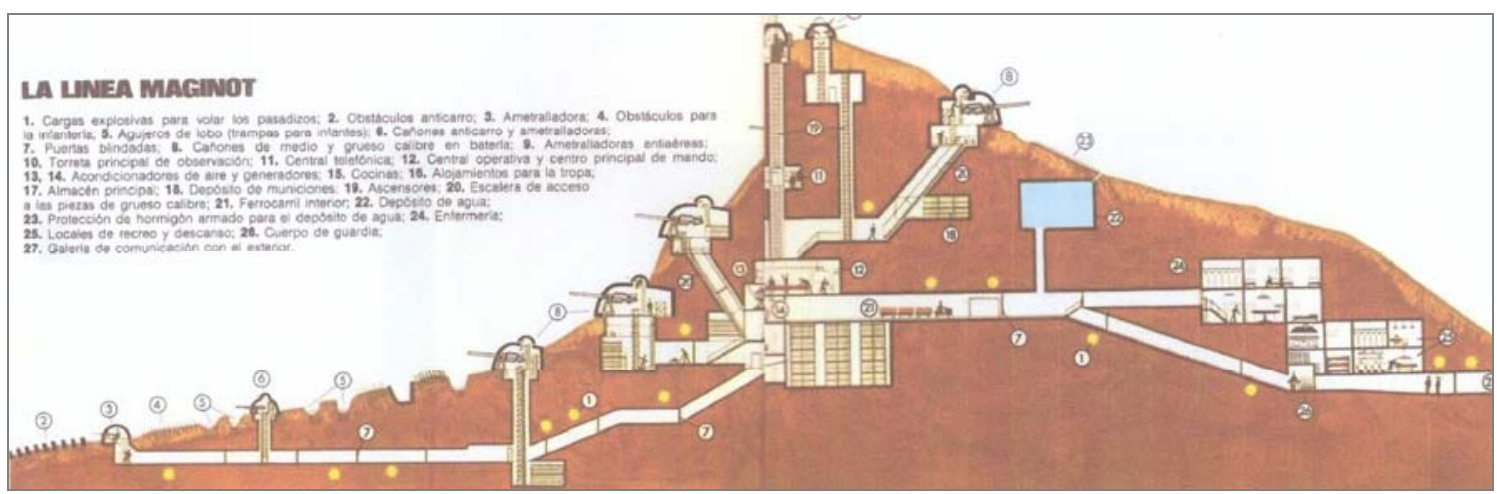

Fig.07: Sección de un complejo de la Línea Maginot (1936, Francia) 


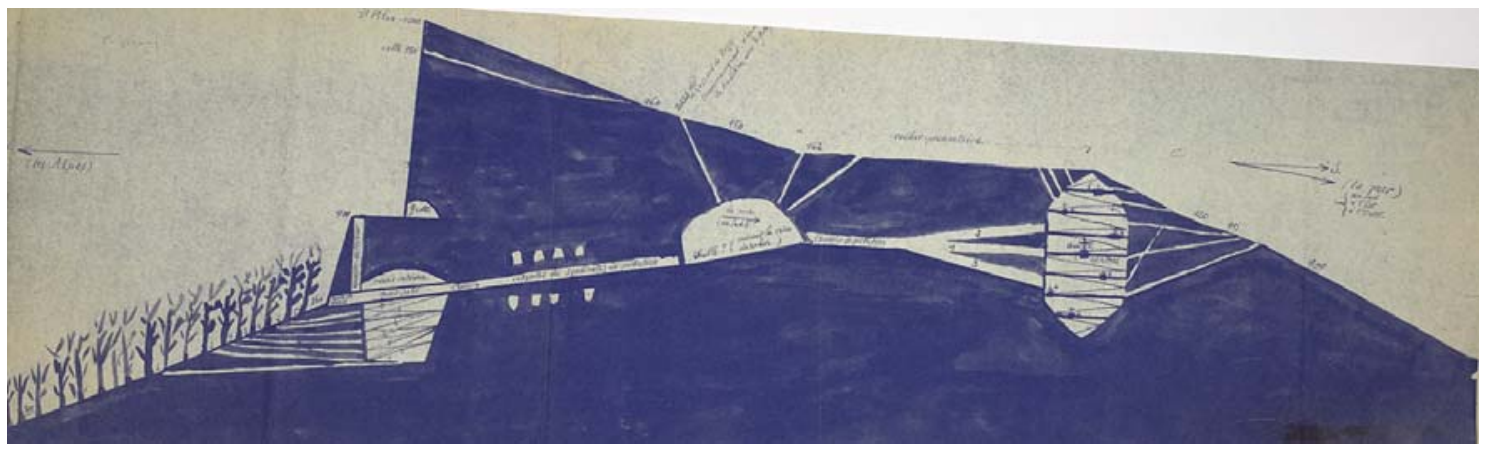

Fig.08: Sección de La Sainte-Baume de Le Corbusier (1945, Francia)

Tampoco resultaría extraña esta proximidad entre lo militar y lo religioso, tanto por la cercanía entre los principios que formuló el maestro suizo para la arquitectura y alguna de sus fuentes: la ingeniería. Más aún, en esta década Le Corbusier investigaba sobre las capacidades resistentes del hormigón frente a los bombardeos: véase su libro de 1938: Des canons, des munitions? Merci! Des Logis... S.V.P. Y en un territorio aún por explorar, quien sabe hasta que punto sus obras brutalistas de hormigón visto que hacen aparición en la década de los 50 no se vieron influidas por el descubrimiento de los búnkeres de hormigón de la guerra y su ensalzamiento como ruinas por parte del filósofo P. Virilio en esos años.

La recurrente desornamentación que caracteriza a ambas arquitecturas (a la moderna y a la militar) poco tiene que ver, en el caso de las defensas, con ninguna convicción estética rupturista, sino que forman parte de una larga tradición de la arquitectura militar por la que los contornos están desprovistos de añadido o postizo alguno que merme su eficacia o no contribuya a su fin bélico. Eficacia y economía en las formas es un precepto que siempre han seguido las arquitecturas utilitarias, máxime las militares. De hecho, en el sentido de la vanguardia de la Nueva Objetividad (que definió la arquitectura como la fórmula científica de función por economía), poco modernas por principio son las características formales y espaciales de estas arquitecturas olvidadas, más allá de la coincidencia de alguno de sus perfiles con bocetos visionarios futuristas o algunas obras construidas expresionistas.

\section{2.- Programa y precisión industrial}

La relación entre los aspectos de 'Función y Tiempo' es donde más afinidades encontramos entre las posiciones de la arquitectura moderna (más conocida por funcionalista) y estas arquitecturas militares. Para el movimiento moderno la función determina la forma: es el programa el que agrupa las partes del modo más eficaz posible. $Y$ los fines de estas defensas están fijados a priori, no son ni cualesquiera ni genéricos y, aunque hoy las veamos sin personas y sin equipo, fueron diseñadas con precisión para un rango preciso de armamento con variantes de tipos ajustados a medida (Manrique 2006). A pesar de que se han perdido los planos originales y muchos libros de referencia, los nombres de los búnkeres a base de siglas y números con que se designan sus homólogos europeos del Atlantic Wall (Rolf 1985 y 1988) sugieren que estos fueron proyectados más como ingenios industriales que como útiles 
artesanales. Antes que arquitecturas, asemejan objetos milimétricamente detallados (Fig. 09): prototipos pensados para montarlos en taller y trasladarlos después a su emplazamiento. Son máquinas petrificadas que, como tales, fueron perfiladas: ajustándose a las exigencias de dominio bélico.

El planteamiento general al que dan cumplimiento todas estas defensas es el de disponer sus aspilleras dirigidas hacia el campo y el cielo de donde se espera la llegada del enemigo mientras se cierran en la parte posterior, la que se considera más segura. Los anchos muros, las estrechas aberturas, sus gruesos techos y sus sólidas cimentaciones refieren con rotundidad su fin: estas arquitecturas están preparadas para defender su posición repeliendo con fuego la incursión enemiga y están hechas para resistir a prueba de bombas: todas las contiendas de la Gran Guerra Civil europea se saldaron con muchas muertes y, sin embargo, con poca destrucción de búnkeres. Sus reducidos espacios interiores están a la medida exacta del armamento con que se equipaban (para su giro, su manejo, su munición) y sus considerables espesores lo son para amortiguar todo tipo de impactos y explosiones. Es probable que estas piezas fueran diseñadas mediante cálculos del efecto de proyectiles y diagramas de resistencia del hormigón armado. Mayor acople de solicitaciones y respuestas es difícil de encontrar en toda la historia de la arquitectura, quizás porque las construcciones militares siempre han sido funcionales, extremadamente eficientes.
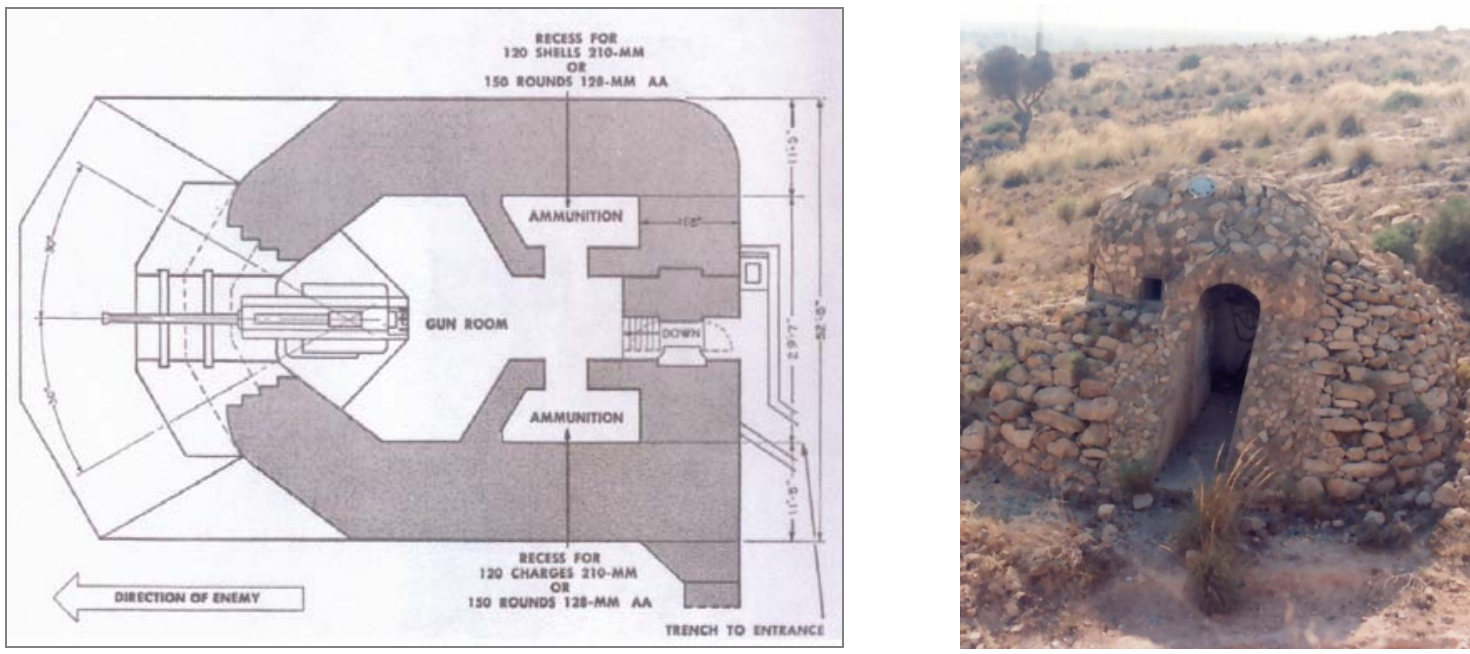

Fig.09: Modelo búnker alemán (1943) Fig.10: Búnker en Clot de Galvany (1937)

En el caso de las defensas del Muro del Mediterráneo se detecta una geometría elemental y una escasa ambición en sus dimensiones frente a las europeas, mucho más elaboradas y sofisticadas. La explicación estaría tanto en que las españolas se ejecutaron años antes como en las circunstancias en que se llevaron a cabo: mientras el Atlantic Wall fue previsto con tiempo y construido por una Alemania poderosa, en España se levantaron con precariedad (1937-38) y con una mano de obra que estaba a su vez en el frente y en la retaguardia. De aquí que no todas presenten homogeneidad de formas y acabados. Los libros de los ingenieros zapadores se desconocen, pero forman parte de la bibliografía especializada de la época como atestiguan los editados 
por otros ejércitos en sus labores de espionaje (Military 1943). Se comprueba, a través de las geometrías de los levantamientos, que las defensas responden a patrones de manual militar, que están diseñadas como piezas industriales ajustando las formas a las exigencias de las demandas bélicas y que están pensadas para su producción en serie (Figs. 11, 12 y 13) aunque se ejecutasen in situ. Nunca la función condicionó tanto la forma como cuando de salvaguardar la vida de sus ocupantes se trataba como garantía de control del territorio. Son antes objetos industriales que piezas de arquitectura.

\section{3.- Material y Técnica}

A pesar de carecer de planos originales (hasta el momento), la geometría de las piezas descubiertas, medidas y dibujadas, revela que los artefactos responden a prototipos previamente diseñados, porque los ejemplos se repiten y aproximan en sus formas de una zona a otra, si bien presentan variantes. Se puede rastrear una genealogía de evolución de las formas más complejas a partir de las más simples siguiendo leyes de adición, giro y abatimiento. Que hubo un profesional en el origen, detrás de cada uno de los asentamientos que se construyeron con la rapidez y urgencia que exigían los acontecimientos bélicos (alguno de ellos sin terminar de ejecutarse), es una cuestión que se pone de manifiesto en las depuradas geometrías recurrentes que se utilizan: prismas y cilindros que sirven, correlativamente, de protectores y de visores para la garantía de su propia defensa. Una defensa que no habría estado lista en tiempo y no habría sido tan eficaz de no haber empleado básicamente hormigón (en masa y armado), un material que se moldea y resulta fácil en su puesta en obra, lo que permite conseguir las formas de los distintos diseños de los catálogos. La resistencia es la razón de ser de estos objetos que cambiaron de bando sin a penas sufrir daños materiales, por lo que se empeñan en soportar el paso del tiempo cuyas huellas surcan con grietas sus acorazadas pieles. Los búnkeres son obstinadas ruinas ahora que ya no tienen un destino.

El hormigón armado es la materia que da corporeidad a superficies opacas y a volúmenes densos. Un material que nace a finales del siglo XIX y que los protagonistas del movimiento moderno proponen como materia idónea para conseguir los ideales de una 'arquitectura nueva' al servicio del 'hombre nuevo' para un 'nueva sociedad'. Es, precisamente, la apariencia pétrea del hormigón la que genera, según el pensador Virilio, este imaginario de 'monolitos modernos', aunque, en el otro extremo, no parece probable que los arquitectos del movimiento moderno pensasen en la larga durabilidad del hormigón como un fin en sus obras pioneras. Más bien, por parte de los vanguardistas, el empleo del hormigón se preveía para estructuras porticadas, más fácilmente destruibles cuando el edificio hubiese consumido su periodo de vida útil, es decir: cuando el uso inicial hubiese quedado desfasado o la solución ya no sirviese adecuadamente al uso previsto (obviamente se trataba de funciones no militares sino civiles). 


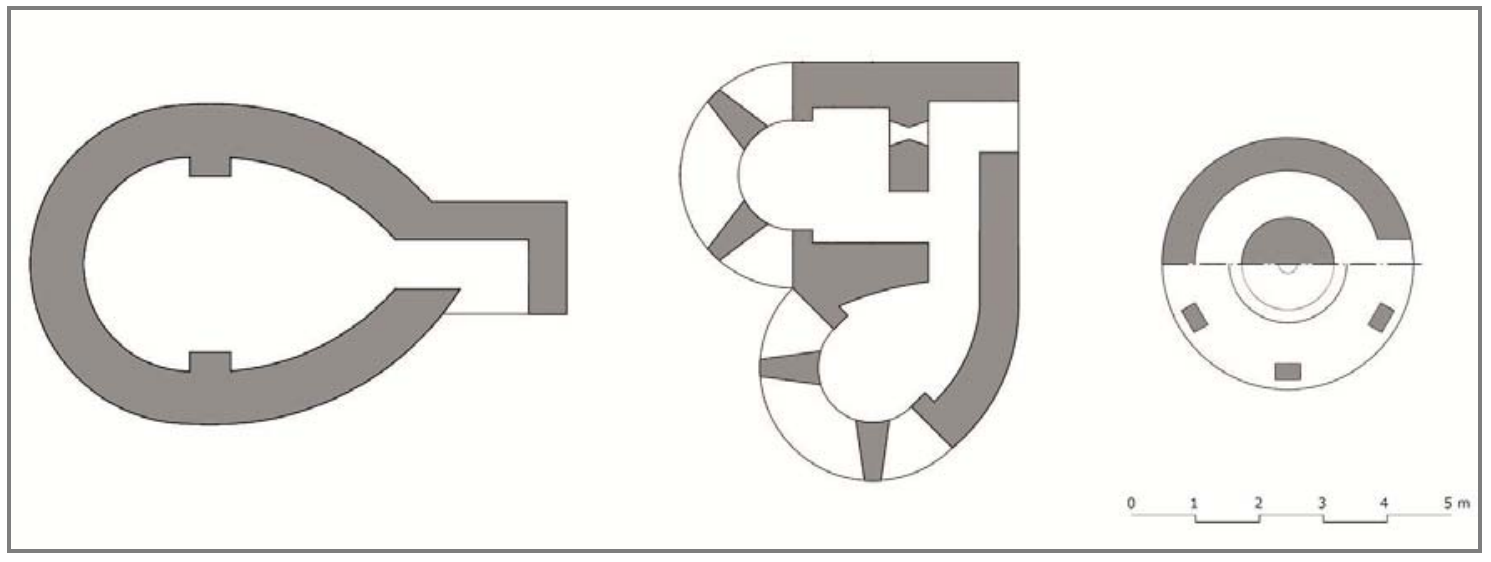

Fig. 11: Búnkeres en cabo Huertas, playa de Altea y Rabasa (1937-38, España)

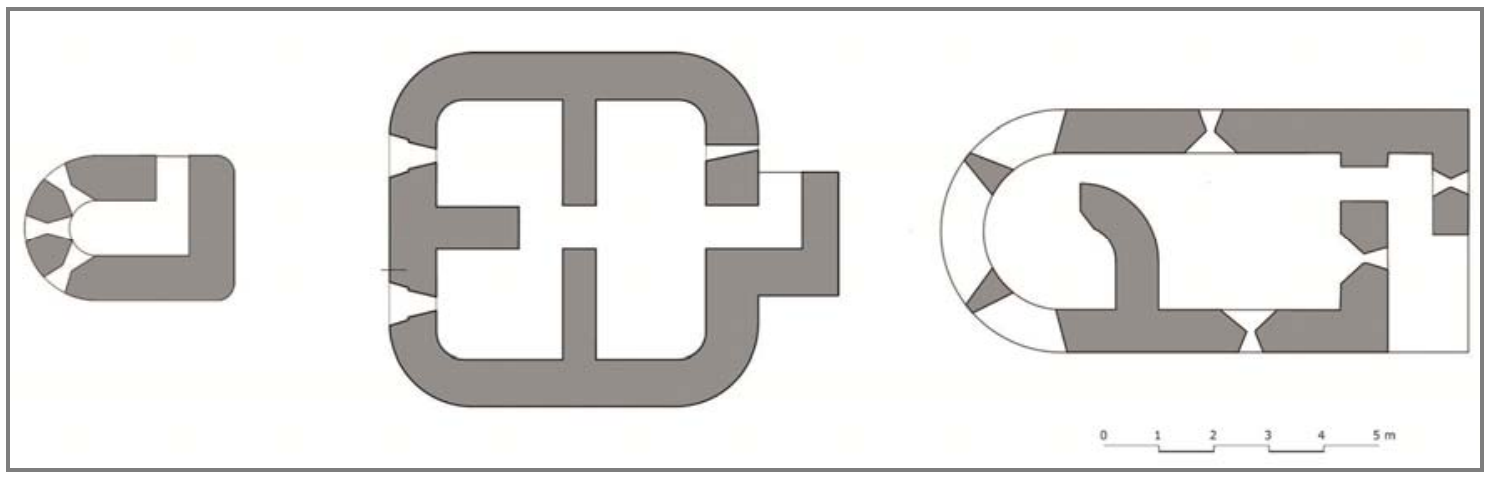

Fig. 12: Búnkeres en el Clot, El Portichol y cabo de Santa Pola (1937-38, España)
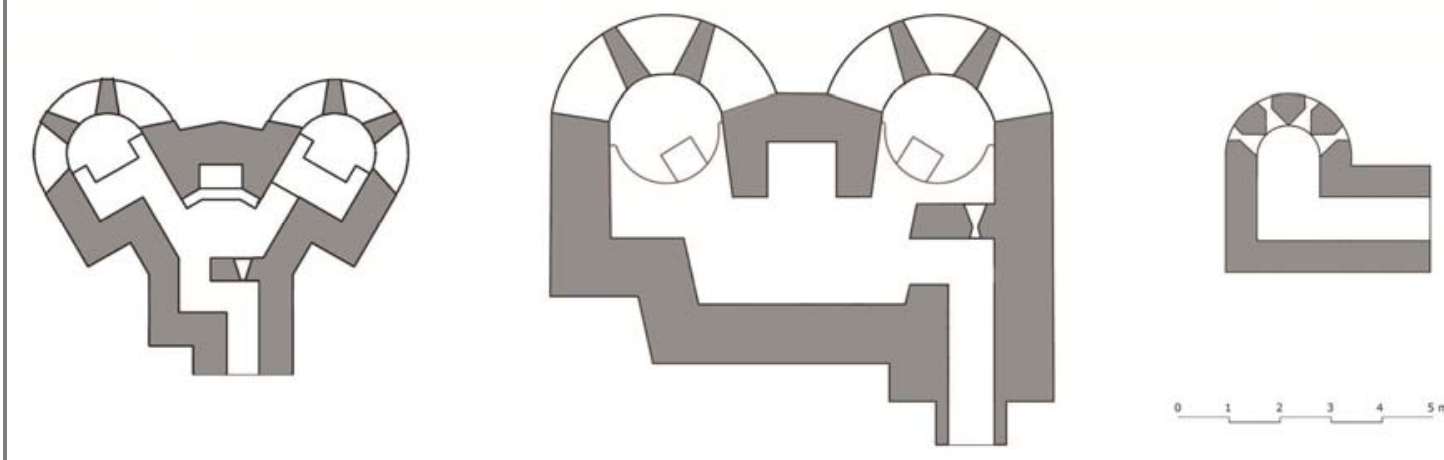

Fig. 13: Búnkeres en el paraje del Clot de Galvany, Elche (1937-38, España)

En las defensas, el hormigón las dotaba de resistencia, las volvía más duraderas, algo no contemplado por el movimiento moderno que pensaba en la sustitución de la arquitectura tras su obsolescencia funcional o técnica. Así pues, el movimiento moderno proponía el hormigón como sustancia idónea para lograr sus fines y, a su vez, su arquitectura tenía una fecha de caducidad ligada a la función. Pero, en nuestro caso, 
el hormigón otorgó la densidad que la volvía imperecedera, situación que divergía de los axiomas del denominado movimiento moderno. Es obvio que al igual que tantos otros objetos útiles como cremalleras, guillettes, gafas de sol, latas o abrelatas, que se validaron tras un conflicto armado (Capella 2011), las dos guerras mundiales fueron el banco de pruebas del hormigón armado como material técnico para la reconstrucción de posguerra. Su validez resultaría universal, más que los principios modernos.

\section{4.- Metamorfosis topográfica}

Sin embargo, la larga vida de estas arquitecturas, que las hace trascender y perdurar hasta nuestros días ( $\mathrm{y}$ con un longevo futuro por delante hasta que como 'ruinas perturbadoras' (Simonnet 2008) se reintegren a la naturaleza), no es una característica que esté en su origen. Su génesis es más sencilla e inmediata: piezas acorazadas y blindadas que garantizaban su función militar como defensas, algo que se conseguía mejor con hormigón, por su monolitismo. La larga vida es un efecto colateral no buscado a propósito. Las arquitecturas olvidadas de la Gran Guerra Civil europea han trascendido la barrera del tiempo planificado gracias al material con que fueron ejecutadas, aunque respondían con precisión a los principios funcionales de compacidad para la resistencia.

En realidad, deberían haber sido destruidas una vez finalizados los conflictos, pero su mantenimiento transformaba la función inicial de los búnkeres de centinelas a guardianes prolongando el imperio del miedo, ya que quien era dueño de estas estructuras también lo era de los destinos de los habitantes de sus vigilados territorios. Ahora, vaciadas de soldados, se da una situación paradójica: ya no deseamos respetar estos axiomas apriorísticos de destruirlas toda vez que ya han cumplido su doble misión de vigilar en la guerra y de amedrentar en la paz. No deseamos borrarlas de la corteza terrestre ni de la envolvente de la memoria común: no queremos que sean arquitecturas olvidadas. Además, no son ajenas a su lugar, suelen identificarse con él.

Porque no puede pasarse por alto su capacidad de camuflaje. Su distribución por el territorio sobre enclaves desde los que repeler los ataques lo es igual de estratégica tanto para controlar el paisaje como en su intención de confundirse con la topografía. Esta singularidad se detecta en todos los búnkeres emplazados en accidentes del relieve (incluidas las plácidas playas) de modo que, parcialmente, se excavan en el lugar (lo que los empotra y los vuelve más indestructibles) y se mimetizan con él: los muros de tongadas de hormigón se ocultan bajo piedras y mampuestos a fin de simular nuevas orografías y pasar desapercibidos ante la mirada ofensiva. El hormigón se metamorfosea en prótesis del medio físico (Fig. 10). Esta táctica militar de mímesis camaleónica permite el acoplamiento del diseño industrial a la forma arquitectónica perfeccionando su función defensiva a costa de adaptarse a la topografía. Quizás la arquitectura sea eso: la feliz intersección entre la geometría y un punto exacto de la geografía, ajustándose a sus particulares accidentes, sean abruptos o llanos. Es en el sitio, mediante la materialización concreta de estos artefactos, donde la ingeniería se transustancia en arquitectura, integrándose en el propio terreno, adoptando su propia piel y fundiéndose con él en una estratégica metamorfosis topográfica. Enterrándose en el suelo, si fuera preciso, hasta el fin de los tiempos. 


\section{4.- CONCLUSIONES: CAMPOSANTO MODERNO A LA MEMORIA DE LAS GUERRAS}

"Sólo hay una pequeña parte de la arquitectura que pertenezca al arte: el monumento funerario y el monumento conmemorativo. Todo lo demás, lo que sirve para un fin, debe quedar excluido del reino del arte". Adol Loos, 1910

Más allá de la seducción romántica que provoca el encuentro con alguna de estas arquitecturas -enclavadas en lugares de gran atractivo paisajístico por su entorno escasamente antropomorfizado, a modo de fragmentos de un esqueleto fosilizado de un animal prehistórico, como antiquísimas ruinas arqueológicas de una civilización desaparecida o como materializaciones físicas, pero abandonadas, de muchas siluetas icónicas de las vanguardias arquitectónicas de entreguerras- se encuentra el significado real del servicio que en su día prestaron estas defensas: servir en guerras fratricidas. Son arquitecturas modernas, no tanto por su imagen epidérmica, distante del imaginario de la Nueva Objetividad, sino porque abrazan desde su génesis los principios modernos: ser el resultado de un proceso en el que se obtienen respuestas formales frente a exigencias funcionales (sin apriorismos) que se decanta del lado de la eficacia técnica y de su coste económico; recorrido muy similar al del diseño industrial, salvo en el hecho de que estos objetos se proyectan como máquinas que tienen la capacidad de adaptarse a lugares concretos. La forma, pues, es el resultado de la función más objetivamente estudiada y calibrada. Más moderna no puede ser esta arquitectura que, incluso, genera sus propios plazos de vida y sus propios mecanismos de adaptación al contexto, superando la asepsia de los productos industriales con los que está genéticamente emparentada, aunque carezca de obsolescencia programada.

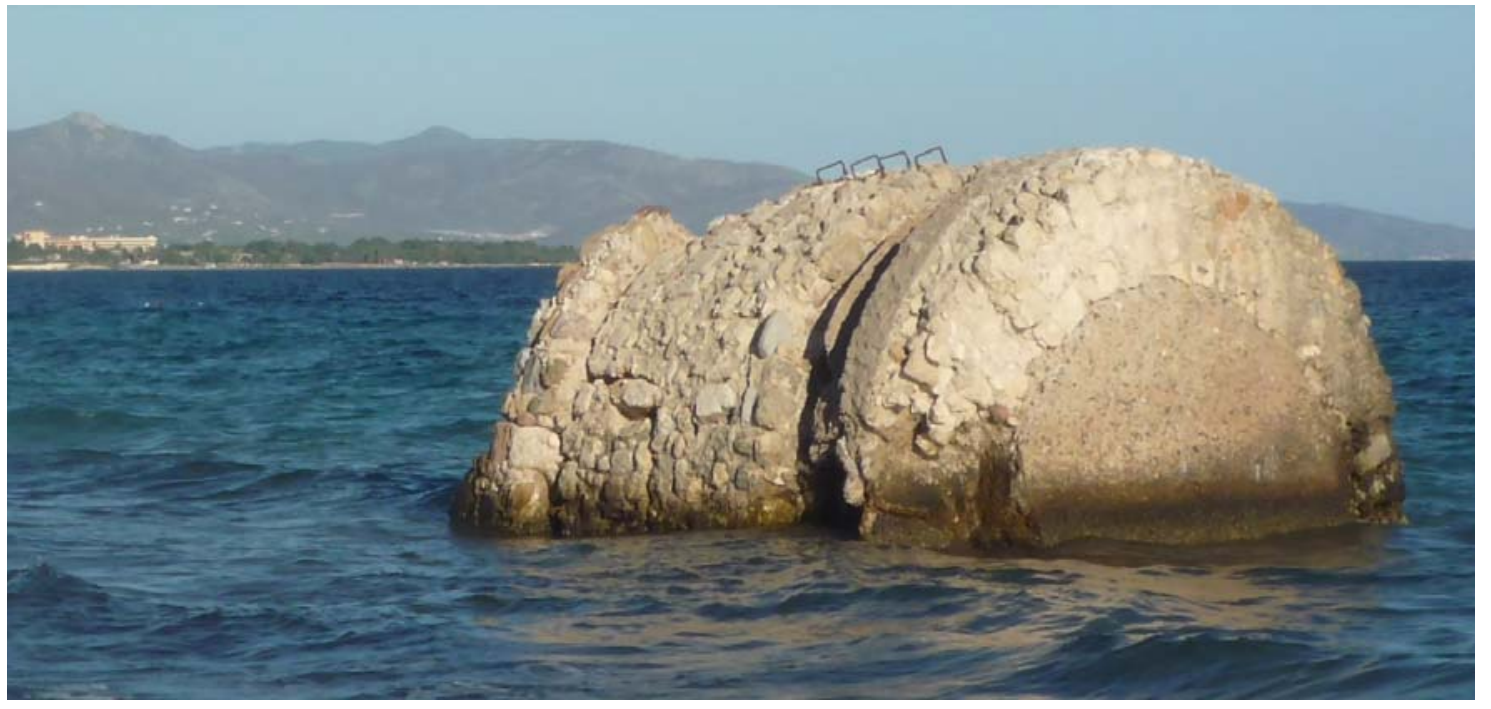

Fig. 14: Búnker varado en la playa de Quartu, Cerdeña (ca. 1942-44, Italia)

Ante esta tesitura quizás convenga parafrasear a $\mathrm{E}$. Panosky quien señalaba que no hay uno sino varios renacimientos (para el Renacimiento) y repensar los límites de la 
arquitectura del movimiento moderno para convenir que hay muchas más arquitecturas modernas, algunas de ellas contradictorias en su imagen, quizás porque "¿No se alimentará la complacencia en el mundo de las imágenes de una obstinación sombría contra el mundo del saber?" (Benjamin 1971). O, quizás, hayamos de admitir que la arquitectura militar siempre ha sido moderna porque ha ido por delante de todas, a la vanguardia, cuestión similar al hecho de que la arquitectura de vanguardia ha sido siempre militante. Arquitecturas, pues, de frontera geográfica y disciplinar y en la frontera entre la vida y la muerte.

Arquitecturas, pues, que se aproximan a la muerte en sus fines y en sus formas: están esparcidas por el territorio y muchas están, en parte, semienterradas, devolviendo a sus usuarios a la tierra madre. Algo de tumbas y de monumentos absurdos, en su corpórea y abandonada presencia, casi ruinosa, tienen todas ellas. $Y$ en arquitectura sólo las tumbas y los monumentos merecen ser considerados arte según A. Loos (Loos 1993). El haberlas vaciado de uso - del programa necesario que las dotaba de sentido para ser arquitecturas- y el haberlas abandonado a su suerte, ha entregado al territorio del arte la antaño ingeniería transformada en arquitectura por la geografía. Estas defensas, al no ser ya utilizadas para sus fines bélicos y propagandísticos, devienen ruinas varadas en paisajes rurales accidentados como los restos de un naufragio esparcidos por la costa. Una especie de camposanto a gran escala se extiende por el espacio bélico moderno articulado por las infraestructuras para la velocidad (del transporte y de las comunicaciones) y los relieves orográficos, del cual emergen los búnkeres como lápidas de 'piedra artificial', modernas. Un cementerio que se extiende, primero, por la costa mediterránea española hasta colonizar todo el Mare Nostrum y, después, por toda la extensión de Europa y que nos afanamos en borrar, haciendo desaparecer nuestro pasado.

La protección y conservación de este paisaje cultural, físico y metafísico, daría cuenta de nuestra nueva sensibilidad que es consciente de los atroces acontecimientos producidos y protagonizados por la humanidad y que conviene no olvidarlos perpetuando la memoria en los restos arquitectónicos. Quizás la conservación no debiera limitarse a una fosilización ni musealización de las ruinas, sino que este vasto cementerio puede ser revalorizado en sus elementos y en su red mediante intervenciones que pongan en primer plano sus valores culturales y permitan -en la línea que señala Solà-Morales (Solà-Morales 1982)- una nueva lectura de estas defensas de la Gran Guerra Civil europea si es que estas arquitecturas aún tienen algo que decir. Asunto que depende de nosotros si queremos aprender de nuestros errores que, como nos recordaba Gandhi, conviene preguntarnos acerca de cuántos hombres más habrán de morir para que nos demos cuenta de que las guerras carecen de razón humana. Si el hombre se enseña por miedo a no tener respuestas, la guerra o, mejor, las arquitecturas que la han hecho posible son el bien patrimonial del cual aprender y transmitir en herencia para perpetuar en la memoria los acontecimientos trágicos de los que es capaz la humanidad y que conviene no olvidar. 


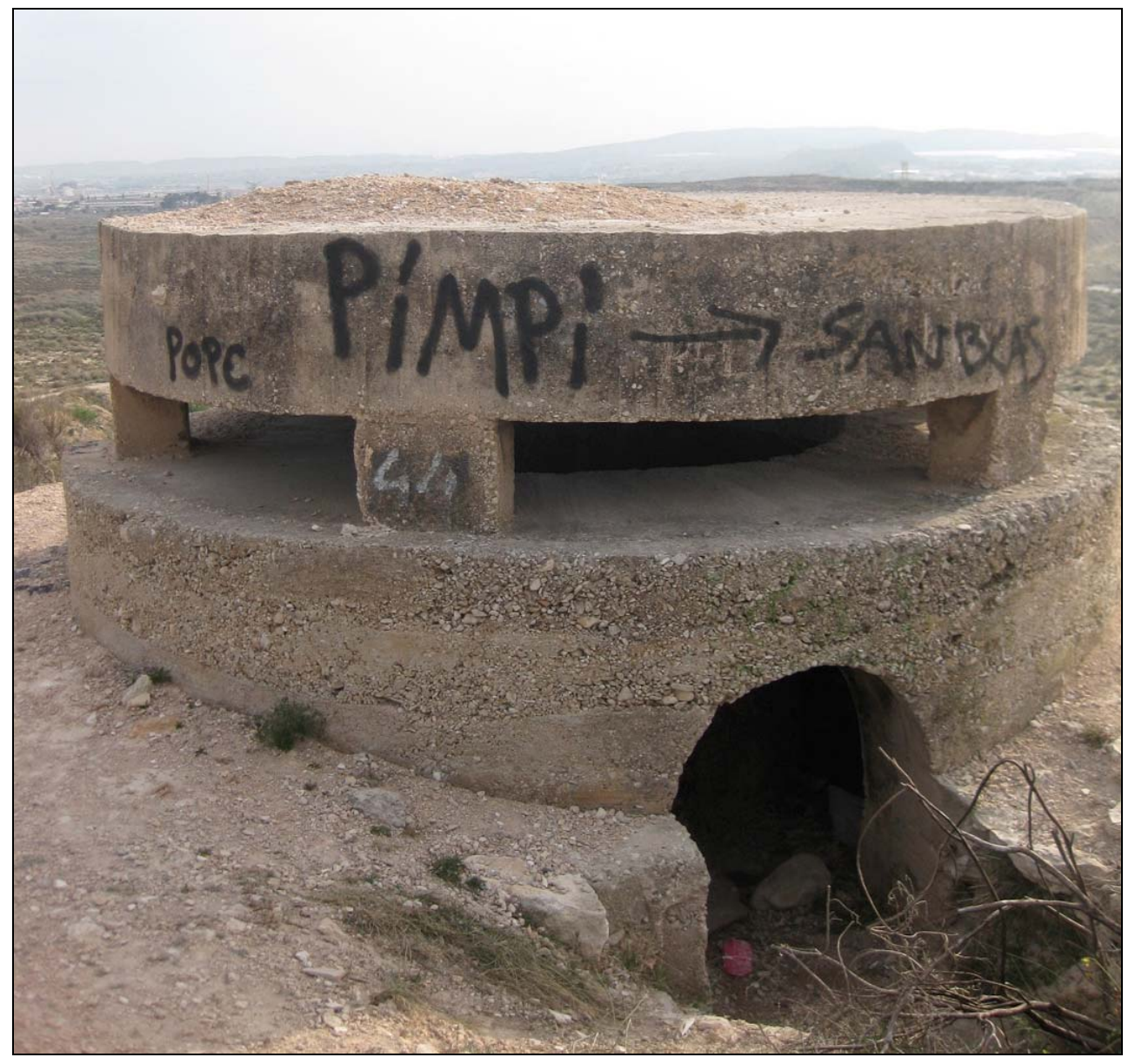

Fig. 15: Estado actual de un búnker en Rabasa, Alicante (1937-38, España)

\section{REFERENCIAS BIBLIOGRÁFICAS}

Aracil, R.; Villarroya, J., El País Valencià sota les bombes (1936-1939), UPV, València, 2010.

Benjamin, W., Discursos Interrumpidos I [ca. 1931], Taurus, Madrid, 1973.

Choay, F., J., Alegoría del patrimonio [1992], Gustavo Gili, Barcelona, 2007.

De la Flor, F., Blocao. Arquitecturas de la Era de la Violencia, Biblioteca Nueva, Madrid, 2000.

García i Mas, A., Martínez i Medina, A.; Ruiz, R., L'arquitectura del medi rural de Santa Pola, ed. Ajuntament, Alicante, 2000.

Loos, A., Escritos II, 1910-1931, El Croquis, Madrid, 1993. 
Manrique García, J.M., Las armas de la Guerra Civil española, La Esfera de los Libros, Madrid, 2006.

Martínez Medina, A., "En defensa de las arquitecturas de la Guerra", Dir. Información, Alicante 16-dic, p: 2, 1997.

Martínez Medina, A., "Dibujando la arquitectura olvidada: las defensas militares de la Guerra de 1936-39" en AA.VV.: Investigación Gráfica. Expresión Gráfica Arquitectónica. Actas: Comunicaciones y Pósters, UPV, Valencia, 2012, pp: 268-274.

Martínez Mira, L., Alicante, 1936-39. Tiempos de guerra, Clara Arts, Alicante, 2005.

Military Intelligence Division, Handbook on German Military Forces, War Department, Washington, 1943.

Mójica Marhuenda, M.J. (dir.), Plan Especial de Protección de las Torres de la Huerta, Ayuntamiento de Alicante, 2002-07.

Postiglioni, G., "El Muro Atlántico: el búnker y/como la arquitectura moderna" en AA.VV., ¿Renovarse o morir?, ed. DoCoMoMo, Barcelona, 2008, pp: 63-68; también $<$ http://www.atlanticwall.polimi.it/>

Rolf, R., Het Duitse fortificatie-ontwerp 1935-1945, AMA, Beetsterzwaag, 1985.

Rolf, R., Atlantic Wall Typologys, Prak Publishings, London, 1988.

Ruiz Núñez, J.B., Floreal del Raspeig en el contexto de las estructuras defensivas de I'Alacanti, Cercle d'Estudis Sequet però Sanet, Valencia, 2012

Simonnet, C., "Le béton éclatant. Esplendor y ruinas" en AA.VV., ¿Renovarse o morir?, Docomomo, Barcelona, 2012, pp: 63-68.

Solà-Morales, I., "Teorías de intervención arquitectónica”, rev. Quaderns, nº 155, 1982.

Tabar Rodríguez, I., Plan Especial de Protección del paraje natural del Clot de Galvany, Ayuntamiento de Elche, 2011.

Tzu, S., El arte de la guerra [ca. 500aC], EDAF, Madrid, 2008.

Virilio, P., Búnker Archeólogie, Centre George Pompidou, Paris, 1975.

Montaje gráfico de los planos: B.P. Morillas Álvarez (estudiante de Arquitectura). 